\title{
Editorial: Urbanistas e Urbanismo no Brasil
}

Editores Responsáveis pelo número

Prof. Dr. Rodrigo de Faria (UnB) e Profa. Dra. Josianne Cerasoli (Unicamp)

O interesse no estudo dos profissionais passa fundamentalmente pela possibilidade de compreensão dos processos de circulação das ideias urbanísticas e sobre os problemas e desafios urbanos de um modo geral. Foram (e são) essas ideias que estruturaram (estruturam) os debates sobre melhoramentos urbanos e planos urbanísticos, planos diretores, planos regionais, o desenvolvimento social-urbano a construção-institucionalização do urbanismo no Brasil, especialmente a institucionalização do campo disciplinar do urbanismo como prática profissional de atuação nas administrações municipais para soluções dos "problemas urbanos": neste caso especialmente pela atuação de engenheiros e urbanistas. Ao mesmo tempo, essas mesmas ideias têm papel importante, mesmo fora do campo dos especialistas, ao instruir paulatinamente as formas de apreensão e entendimento do urbano.

A institucionalização do urbanismo no âmbito das administrações municipais compreende uma conjuntura profissional e institucional em construção desde o século XIX, com as primeiras Comissões de Melhoramentos, como a do Rio de Janeiro na década de 1870; as Diretorias de Engenharia e Obras Públicas, onde uma primeira geração de engenheiros-urbanistas desenvolveu suas atividades; as Seções de Cadastro e Urbanismo, como a organizada durante a atuação do engenheiro Victor da Silva Freire em São Paulo na década de 1920; as Comissões de Planos da Cidade, já no contexto histórico do Estado Novo; ou ainda as experiências autorais individuais, tais como de Nestor de Figueiredo e seu Plano para João Pessoa.

Nessa primeira conjuntura histórica de atuação profissional no campo do urbanismo, os profissionais atuaram fundamentalmente na infraestruturação e modernização urbana, geralmente com intervenções em canalização de rios, implantação de sistemas ferroviários, de sistemas de abastecimento de água e canalização de esgoto, iluminação pública, ajardinamento de áreas livres, entre outras. Todavia, não desconsideravam os processos mais amplos, prevendo e orientando a expansão urbana, como foi o caso do Plano do Novo Arrabalde em Vitória elaborado pelo engenheiro Francisco Saturnino de Brito, publicado em 1896 . 
É neste primeiro movimento de atuação profissional que o processo de construção-circulação das ideias urbanistas sobre a intervenção nas cidades adquiriu uma dimensão internacional, sobretudo nas décadas de 1910 e 1920. Nesse momento, o diálogo aberto com profissionais de outras nacionalidades é fundamental para o aprofundamento do campo conceitual e do vocabulário erudito de intervenção nas cidades (TOPALOV e DEPAULE, 2001, p. 17-38) brasileiras, principalmente os diálogos que ocorreram nos debates sobre a contratação de Alfred Agache para a elaboração do "Plano de Remodelação, Embelezamento e Extensão do Rio de Janeiro", publicado em 1930, simultaneamente à apresentação de croquis por Le Corbusier propondo para Capital Federal uma grande estrutura urbana que articulava a paisagem natural do Rio de Janeiro (PEREIRA, 1996, p.396-376; DE FARIA, 2007).

A articulação com profissionais de diferentes nacionalidades ocorre também em outro sentido, a partir do próprio Brasil, pela interlocução profissional empreendida pelos profissionais brasileiros. Dois exemplos que não são os únicos e nem mesmo as únicas formas de articulação são ilustrativos dessa articulação: o diálogo empreendido por Victor da Silva Freire com estudos e profissionais europeus ao menos em dois importantes artigos, "Melhoramentos de São Paulo" e "Cidade Salubre" (de 1911 e 1914, respectivamente), discutindo os problemas da capital paulista em diálogo, por exemplo, com os estudos realizados por Camillo Site ainda no século XIX; e a formação como urbanista de Atílio Correia Lima na França, que no posterior retorno ao Brasil passa a atuar profissionalmente tanto no ensino na ENBA (convidado por Lucio Costa), como na atividade de projeto urbanístico (plano inicial de Goiânia).

No âmbito da institucionalização e prática urbanística nas administrações municipais brasileiras, é necessário referir-se aos Departamentos de Urbanismo no contexto da redemocratização legitimada pela Constituição Municipalista de 1946, especialmente, mas não os únicos, o Departamento de Urbanismo da Prefeitura do Rio de Janeiro organizado e dirigido inicialmente pelo engenheiro José de Oliveira Reis, e o Departamento de Urbanismo de São Paulo criado em 1947 no bojo dos debates profissionais entre os engenheiros Prestes Maia e Luiz de Anhaia Mello (FELDMAN, 2005).

Está nesse movimento pela criação contínua das instituições de urbanismo, pós1940 e ao longo das décadas de 1950 e 1960, um debate sobre o planeamento municipal, não mais limitando à atuação profissional e a própria compreensão sobre urbanismo e planejamento urbano, restrito às áreas urbanas dos municípios. Da mesma forma, estimula-se o debate profissional e institucional sobre dimensão regional do desenvolvimento, pelo que deveria considerar em termos de processos de URBANA, V.5, no 7, out.2013 - Dossiê: Urbanistas e Urbanismo: a escrita da história... - CIEC/UNICAMP 
cooperação intermunicipal para a elaboração de planos regionais, ou ainda, a cooperação interestadual, como no caso da Comissão Interestadual da Bacia ParanáUruguai, CIBPU (FELDMAN, 2008). E aqui outro importante momento de interlocução profissional internacional com as visitas de Pe. Lebret ao Brasil e a criação da Sociedade para Análise Gráfica e Mecanográfica Aplicada aos Complexos Sociais (SAGMACS, envolvida nos trabalhos da CIBPU) no ambiente intelectual do Movimento Economia e Humanismo (ANGELO, 2010), e suas vinculações com profissionais brasileiros, entre eles Antônio Bezerra Baltar em Recife e Antônio Delorenzo Neto em São Paulo.

Na década de 1960, especificamente na transição entre a redemocratização pós-1946 e o Golpe Militar de 1964, o processo de institucionalização do urbanismo na administração pública brasileira foi incorporado no governo federal com a criação do Serviço Federal de Habitação e Urbanismo (SERFHAU), juntamente com a criação da instituição financeira para gerir os recursos federais no âmbito das políticas urbanas, o Banco Nacional de Habitação. No caso do SERFHAU, destaca-se, sobretudo a atuação de Harry James Cole (LUCCHESE, 2009) após processo de reformulação do órgão em 1966, tendo desse processo participado e nesse contexto defendendo e divulgando a necessidade do planejamento urbano e dos planos locais integrados.

Desde a atuação nos municípios brasileiros passando pelo governo federal, muitos foram os profissionais urbanistas que durante os congressos e nas revistas especializadas apontavam a necessidade de criação de um órgão federal de urbanismo, tal como consta em artigos apresentados no I Congresso Brasileiro de Urbanismo em 1941, especialmente a proposta de criação do Departamento Nacional de Urbanismo (MARTINS, 1941, p. 128-131) feita pelo engenheiro Mario de Souza Martins, incluída como recomendação nas conclusões da Seção I - História e Divulgação, presidida por Atilio Correia Lima no I Congresso Brasileiro de Urbanismo, em 1941.

Processo histórico que passa pela criação da Comissão Nacional de Políticas Urbanas e Regiões Metropolitanas no âmbito do II PND na década de 1970, com a atuação de Jorge Franciscone e Maria Adélia de Souza, aponta a clara articulação multidisciplinar de atuação nos temas urbanos e urbanísticos, ele formado Arquiteto, ela Geógrafa, e que não pode desconsiderar o debate urbanístico ocorrido no Brasil em função do concurso para Brasília no final da década de 1950. Este debate foi claramente marcado pela interlocução dos profissionais brasileiros com as discussões realizadas no âmbito dos Congressos Internacionais de Arquitetura Moderna, os CIAM. 
Nesse contexto histórico largo está a importância dos estudos sobre a atuação profissional de urbanistas e pensadores da "questão urbana" no Brasil - profissionais atuantes no Brasil nos séculos XIX e XX e permanecem como referências intelectuais de primeira grandeza para o contínuo processo de compreensão-intervenção nas cidades brasileiras.

Os artigos publicados neste dossiê vêm a público em dois números consecutivos da Revista Urbana ( 6 e 7) e tiveram origem em intensos debates realizados em torno dessas questões durante o seminário Trajetórias: urbanistas e urbanismo no Brasil, realizado em Brasília, em abril de 2013, organizado pelo Grupo de Pesquisa em História do Urbanismo e da Cidade $-\mathrm{UnB} / \mathrm{CNPq}$, pela Faculdade de Arquitetura e Urbanismo e Programa de Pós-Graduação em Arquitetura e Urbanismo - UnB, pelo Centro Interdisciplinar de Estudos da Cidade - Unicamp e pela Rede Urbanismo no Brasil - USP/CNPq.

\section{Referências}

TOPALOV, C.; DEPAULE (2001). A cidade através de suas palavras. In: BRESCIANI, Maria S. Martins (org.). Palavras da Cidade. Porto Alegre: EDUFRGS.

PEREIRA, Margareth da Silva (1996). Pensando a metrópole moderna: os planos de Agache e Le Corbusier para o Rio de Janeiro. RIBEIRO, Luis C. de Q; PECHMAN, Robert (org.). Cidade, povo e nação - gênese do urbanismo moderno. Rio de Janeiro: Civilização Brasileira.

DE FARIA, Rodrigo Santos (2007). José de Oliveira Reis, urbanista em construção: uma trajetória profissional no processo de institucionalização do urbanismo no Brasil (1926-1965/1966) / Tese de Doutorado em História. Universidade Estadual de Campinas.

FELDMAN, Sarah (2005). Planejamento e Zoneamento. São Paulo: 19471972. São Paulo: EDUSP/FAPESP.

FELDMAN, Sarah (2008). 1950. A década de crença no planejamento regional no Brasil. Anais do XI ENANPUR.

ANGELO, Michelly Ramos de (2010). Les développeurs Louis-Joseph Lebret e a SAGMACS na formação de um grupo de ação para o planejamento urbano no Brasil. Tese de Doutorado. Escola de Engenharia de São Carlos (EESC-USP).

LUCCHESE, Maria Cecília (2009). Em defesa do planejamento urbano ressonâncias britânicas e a trajetória de Harry James Cole. Tese de Doutorado. Escola de Engenharia de São Carlos (EESC-USP).

MARTINS, Mario de Souza (1941). Da Criação do Departamento Nacional de Urbanismo. Revista Municipal de Engenharia, PDF. 